\title{
Crítica Waratiana à Teoria do Direito: Os Mitos do Ensino Jurídico Tradicional
}

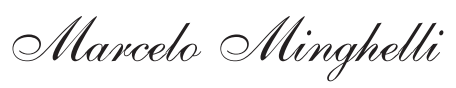

Mestrando em Direito pela UFPR.

\section{SUMÁRIO}

\section{Introdução;}

1 A teoria pura do direito; 1.10 posicionamento da teoria pura perante a dogmática jurídica; 1.2 O processo de recuperação ideológica da teoria pura do direito; 1.3 A necessária crítica à teoria pura do direito;

2 A purificação política e ideológica;

3 A purificação antijusnaturalista;

4 A purificação antinaturalista ou anticausalista;

5 A purificação intranormativa;

6 A purificação monista ou antidualista;

70 ensino jurídico tradicional;

Considerações finais;

Referências bibliográficas.

\section{Introdução}

“(...) Suponhamos uns homens numa subterrânea em forma de caverna, com uma entrada aberta para a luz, que se estende a todo o comprimento dessa gruta. Então lá de dentro desde a infância, algemados de pernas e pescoços, de tal maneira que só lhes é dado permanecer no mesmo lugar e olhar em frente; são incapazes de voltar as cabeças, por causa dos grilhões; serve-lhes de iluminação um fogo que queima ao longe, numa eminência, por detrás deles; entre a fogueira e os prisioneiros há um caminho ascendente, ao longo do qual se construiu um pequeno muro, no gênero dos tapumes que os homens dos $<<$ robertos $>>$ colocam diante do público, para mostrarem suas habilidades por cima deles.

(...) Visiona também ao longo deste muro, homens que transportam toda espécie de objetos, que o ultrapassam: estatuetas de homens e animais, de pedra e de madeira, de toda a espécie de lavor. 
(...) Em primeiro lugar, pensas que, nesta condições, eles tenham visto, de si mesmo e de outros, algo mais que sombras projetadas pelo fogo na parede oposta da caverna ?"1 (PLATÃO, 1996, p. 317)

PLATÃO continua a alegoria da caverna libertando um de seus habitantes dos grilhões, este anda em direção a luz e, saindo de sua prisão, enxerga a realidade. $\mathrm{Ob}$ serva que as sombras produzidas no interior da caverna não passam de meros reflexos da realidade e que todo o seu sistema de vida é fundado sobre aparências. Obviamente, esta realidade fere não só sua visão como sua compreensão sobre o mundo, causando-lhe dor e angústia, pois não possuía mecanismos para decifrar este novo conjunto sensível que lhe é apresentado. Mas, aos poucos, acostuma-se com a realidade, começa a descrevê-la com novas significações e percebe que os habitantes da caverna também devem conhece-la.

No entanto, seus habitantes estão acostumados com seu cômodo sistema de vida, seus olhos não reagem bem à luz do sol e qualquer um que ouse questionar a sua falsa realidade pode ser taxado como louco e até mesmo condenado à morte como charlatão. A realidade, como a luz aos olhos de um cego, deve ser trazida aos poucos para que os habitantes se acostumem a novas concepções de vida. É preciso consolidar gradativamente a realidade.
A referência ao mito da caverna é pertinente no presente trabalho, pois o objetivo do mesmo é colaborar com a consolidação de um conhecimento crítico acerca da Ciência do Direito. Não com a arrogância de quem possui o domínio da realidade, mas com a experiência frustrante de perceber as falsas significações impostas pelas sombras da caverna ao mesmo tempo em que não se possui conhecimento suficiente para entender e descrever a realidade devido ao longo tempo de exposição às sombras. Significa dizer que um acadêmico de Direito inserido em um ensino jurídico dominado pela dogmática jurídica tradicional, ao ter contato com uma perspectiva crítica do Direito, pode optar definitivamente pelas concepções do antigo paradigma ou então, optando pela luz, pode cegar-se parcialmente, construindo um conhecimento fragmentado e insuficiente para orientálo dentro da nova realidade.

É desta forma que tentar-se-á abordar a crítica de LUIZ ALBERTO WARAT acerca da Teoria Pura do Direito elaborada por KELSEN. Crítica que expõe os mitos, as ideologias e as contradições escondidas nas sombras do senso comum teórico dos juristas. Dentro desta perspectiva de consolidar um conhecimento crítico através da facilitação, onde se busca a familiarização do acadêmico de Direito com novas concepções e significações, pode-se chegar apenas a um mero reflexo da realidade, mas, no entanto, este deverá apontar para a luz.

1 Esses trechos foram extraídos do Livro VII da República, referentes à alegoria da caverna. Foram transcritas apenas as partes necessárias para possibilitar uma descrição mínima da alegoria que será utilizada no decorrer do capítulo. Deixamos claro que 0 presente estudo não tem por objetivo aprofundar-se nas significações da obra do filósofo grego, a utilização do mito da caverna justificar-se-á no decorrer do trabalho. Para maior compreensão vide REALE, Giovanni e ANTISERI, Dário. História da Filosofia Antiga. Paulos, 1994. 


\section{A teoria pura do direito}

Antes de mais nada se faz necessário identificar a Teoria Pura do Direito formulada por KELSEN como uma teoria geral do Direito que tem como objetivo descrever o quê e como é o Direito, não existindo a pro cura por uma justificação, explicitação, ou mesmo por uma desclassificação do mesmo.

Neste processo, KELSEN adota o princípio metodológico da pureza, sem o qual, segundo ele, seria impossível determinar a autonomia da Ciência Jurídica. Desta forma afasta a possibilidade de interdisciplinaridade do Direito, considerando a sociologia, a ética e a teoria política como elementos estranhos. O conhecimento jurídico deve ser dirigido ao Direito, excluindo tudo o que não puder ser determinado como tal. (WARAT, 1995, p. 150)

Este Direito, objetivo do conhecimento jurídico, é considerado como sistema de normas postas pela autoridade jurídica que regulam o comportamento humano (CORRÊA, 1991, p. 11).

Temos portanto, através da perspectiva kelseniana, uma ciência jurídica cujo objeto é o conjunto de normas postas pelas autoridades jurídicas, o Direito em sentido estrito, o Direito Positivo, e cuja única função é descrever seu objeto, sem procurar justificá-lo ou qualificá-lo, ou seja, para KELSEN a ciência jurídica não prescreve, não cria, não modifica o Direito, não interage com seu objeto.

\subsection{0 posicionamento da teoria pura perante a dogmática jurídica}

A função da ciência jurídica determinada por KELSEN traz como conseqüências a sua inércia quanto a produção de significações dos órgãos do sistema jurídico. Cria-se uma distinção entre os enunciados da Ciência do Direito ${ }^{2}$ que devem seguir o princípio metodológico da pureza e as normas produzidas pelos órgãos jurídicos, com o objetivo de impedir a contaminação promovida pela dogmática jurídica, através do núcleo teórico do Direito Natural carregado de categorias metafísicas, conceitos com falsas evocações referenciais, topoi revestidos de categorias explicativas desempenhando funções retóricas. ${ }^{3}$

Cabe aqui uma contextualização, pois a dogmática jurídica determinante do

2 Para KELSEN a Ciência do Direito pode produzir apenas proposições objetivas, limitando-se a descrever seu objeto (normas jurídicas), da mesma forma que as leis naturais da ciência da natureza, ou seja uma descrição alheia aos valores. Desta forma, a resposta dada pela ciência jurídica, à questão se uma determinada conduta é contrária ao Direito, como afirma KELSEN (1991, p. 90): "é uma afirmação se esta conduta é prescrita ou proibida, cabe ou não na competência de quem a realiza, é ou não permitida, independente do fato de o autor da afirmação considerar tal conduta como boa ou má moralmente, independente de ela merecer sua aprovação ou desaprovação". Tem-se a distinção severa do cientista jurídico com a autoridade jurídica e uma proposição (ciência do Direito) que não pode se tornar uma prescrição (norma jurídica).

Observa-se, porém, que este objeto (normas jurídicas) possuem valores jurídicos não reveladas na proposta normativista kelseniana e que a relação de influência da ciência jurídica na produção de normas jurídicas é subestimada.

3 É preciso esclarecer que a concepção de purificação adotada impõe à ciência jurídica o afastamento das questões vinculadas à produção e aplicação das normas, pois neste momento haveria um juízo valorativo, axiológico, incompatível com a concepção da ciência adotada por KELSEN. Esta seria a tarefa da Política Jurídica. Abordar essas questões, dentro da ciência do direito, significaria a quebra das fronteiras entre ciência e política, entre ideologia e verdade (WARAT, 1995, p. 151). 
paradigma de Ciência do Direito, na época da formulação da Teoria Pura, possuía um núcleo teórico abastecido pelas significações produzidas pelo Direito Natural. Essa significações, para KELSEN, eram carregadas de uma função ideológica ${ }^{4}$ que tinham como objetivo legitimar um determinado ordenamento jurídico, criando uma situação impeditiva de construção de uma ciência jurídica comprometida com a verdade.

A dogmática jurídica estabelecia um processo retórico, um processo de argumentação, um discurso para legitimar a ordem dominante. Esse discurso produzia e, ao mesmo tempo, era formado por topois que são lugares comuns de significação de onde se parte para o processo retórico, para o processo de convencimento. Essas significações são cristalizadas e reproduzidas pelo stablishment jurídico ${ }^{5}$ e acabam por formar um senso comum teórico dos juristas.

À Teoria Pura do Direito se contrapõe esse processo utilizando-se dos critérios do positivismo científico para estabelecer um novo paradigma que impediria as influências ideológicas produzidas pelo núcleo teórico da dogmática jurídica norteado pelo Direito Natural.

Em resumo, KELSEN produz um conhecimento normativo do Direito que, como afirma WARAT (1995, p. 157), “(...) exclui de seu objeto toda ideologia e prática política, qualquer contribuição proveniente da filosofia da justiça, da moral, da religião e, ainda, crenças, princípios e categorias que regulam a constituição das ciências causais, como também as pseudo-categorias do pensamento jurídicoclássico".

\subsection{0 processo de recuperação ideológica da teoria pura do direito}

Chega-se a um ponto crucial do normativismo kelseniano, pois os critérios estabelecidos para a Ciência do Direito, de cunho positivista, e a adoção do princípio da pureza metodológica, que tem como objetivo conferir aos seus resultados o ideal de toda ciência, qual seja, objetividade e exatidão, cria a ilusão perigosa de que a ciência não cumpre uma função social, além de produzir um novo retórico a serviço das funções que se pretendia eliminar (WARAT, 1995, p. 156).

WARAT afirma ter existido um processo de recuperação ideológica ${ }^{6}$ da Teoria Pura do Direito por parte da dogmática jurídica. Esta sempre teve por objetivo mascarar as ideologias e valores escondidos em seu discurso, e KELSEN, ao adotar regras

4 A definição de ideologia utilizada no presente trabalho é dada como um instrumento retórico de dominação: "Ideologia é o conjunto orgânico de idéias, representações, teorias, crenças e valores, orientando para a legitimação ou reprodução da ordem estabelecida, expressando os interesses vinculados aos grupos ou classes dominantes, através de um discurso dissimulador das contradições e antagonismos sociais, em nome de uma pretensa unidade social." (CORRÊA, 1999, p. 29).

5 O termo utilizado define o conjunto de órgãos institucionais como faculdades de Direito, parlamento, tribunais associações de profissionais e a administração pública que reproduzem um discurso de fetichização do Direito. Sobre o assunto, ler STRECK, Lênio Luiz. Hermenêutica Jurídica em Crise.

6 "Entende-se por recuperação ideológica, em sentido lato, os mecanismos de argumentação por meio dos quais são redefinidos os sentidos críticos, para readaptá-los à função de representação ideológica dos discursos tradicionais." (WARAT, 1995, p. 161) 
da racionalidade positivista, cria uma nova possibilidade de utilização retórica de significações. Se antes a dogmática jurídica utilizava-se de núcleo teórico de Direito Natural, agora ela utiliza-se de novos mitos, introduzidos pela própria Teoria Pura do Direito. A objetividade, a exatidão e a neutralidade são as novas máscaras do discurso dogmático, agora modernizado e mais competente.

Desta forma a Teoria Pura do Direito de viés positivista mostra uma grande limitação como teoria crítica do saber dominante, não conseguindo explicitar a complexidade do fenômeno jurídico inserido na realidade social, passando a integrar, através do processo de recuperação ideológica, a dogmática jurídica.

\subsection{A necessária crítica à teoria pura do direito}

O normativismo kelseniano fracassa enquanto instância crítica da dogmática jurídica, ou seja, tanto seu viés positivista quanto o princípio da pureza metodológica mostram-se insuficientes para impedir o processo de recuperação ideológica e a própria Teoria Pura transforma-se em dogmática jurídica.

Essa dogmática jurídica continua cumprindo sua função de legitimação da ordem dominante, mas agora, seu discurso retórico é atualizado. Através dos princípios metodológicos do positivismo científico, inserido pela proposta kelseniana, cria-se ilusão de uma ciência jurídica exata e objetiva, livre de influências ideológicas, quando na verdade este novo paradigma é incapaz de realizar sua própria proposta, não consegue descrever a realidade, pois, como afirma CORRÊA (1999, p. 16): "Não se pode captar a complexidade da realidade social pela mera descrição do que é visível, pela simples experiência sensível. $\bigcirc$ pensamento positivista fracassado justamente por seu viés metodológico unilateral e limitado na tentativa de compreensão de um mundo complexo e contraditório. A realidade é movimento, processo constante."

Assim, perante a limitação da Teoria Pura do Direito e sua cristalização enquanto dogmática jurídica, WARAT propõe um verdadeiro desmembramento do processo de purificação estabelecido por KELSEN, através do qual a proposta kelseniana de construção de um conhecimento jurídico dirigido às normas e auto-consciente de sua especificidade se estabelece, para se vislumbrar uma nova perspectiva crítica da dogmática jurídica.

\section{A purificação política e ideológica}

A idéia central deste nível de purificação reside na seguinte fórmula: "É necessário distanciar os saberes específicos do Direito das concepções jurídicas tradicionais preocupadas em sustentar alguma ideologia social, em implementar certos interesses. E ainda envolta em raciocínios de política jurídica ou especulações endereçadas à formulação de Direito." (WARAT, 1995, p. 163)

O conhecimento jurídico deve separar-se severamente da política de tal forma a excluir do objeto teórico tudo aquilo que faz referência às valorações ideologicamente construídas bem como limitar-se a realizar 
uma análise estruturante do Direito Positivo. Significa dizer que a Ciência do Direito não poderá exercer uma função de orientação dos órgãos de autoridade jurídicos, não indicará possíveis resoluções de problemas sociais, econômicos ou políticos e nem terá a função de valorar as posições já tomadas. A Ciência do Direito, conforme KELSEN, pode afirmar apenas como o Direito é, porém, nunca poderá afirmar como deverá ser. Esta postura visa estabelecer o caráter antiideológico da Ciência Jurídica na medida em que, para KELSEN, a ideologia veda a realidade, pois toda ideologia política tem suas raízes na vontade, é emocionalmente constituída e não racionalmente.

A Teoria Pura do Direito, seguindo o princípio da pureza metodológica, renega o dualismo entre Política e Direito e sua influência na determinação da sociedade, esquecendo-se da dimensão jurídica da política e da dimensão política do Direito. Em suma, o papel político desempenhado pelo Direito na sociedade não é abordado em nome do princípio da pureza que confere à Ciência Jurídica um conhecimento verdadeiramente imunizado contra a ideologia.

WARAT critica esta abordagem afirmando que a postura kelseniana, de negar a tematização das significações ideológicas favorece o papel ideológico do conhecimento. Afirma, ainda, que o conhecimento científico crítico só seria alcançado quando este puder explicar as significações ideológicas. Temos, portanto, uma abordagem limitada a respeito do Direito, que esconde as significações ideológicas, como afirma CORRÊA (1999, p. 22): "Fazer ciência compreensiva do Direito significa abordar interdis- ciplinarmente a juridicidade, desvendando seus condicionamentos, seus fundamentos ético-políticos, sua não neutralidade no processo de construção da globalidade das relações sociais."

KELSEN não só limita a compreensão do fenômeno jurídico como também encobre a função social da ciência jurídica negando a relação da influência existente entre o processo de produção de significações produzidas pelos órgãos institucionais politicamente determinado e o processo de produção de significações da Ciência do Direito determinado de maneira objetiva e neutra. Significa dizer que a ciência trabalharia com sentidos produzidos fora de uma relação de poder influenciadora, quando na verdade, como afirma WARAT (1995, p. 177), “(...) a significação jurídica é sempre resultado de um ato político; os discursos jurídicos fazem ouvir sempre aos sujeitos do poder".

Essa ficção criada pelo mito da neutralidade científica, que nega a relação entre ciência e política, obscurece e camufla as teorias sociais e políticas, facilitando a sua inserção e cristalização no domínio da ciência dominante.

Portanto, uma perspectiva crítica de Ciência do Direito deve ter como tarefa esclarecer a sua função social, ou seja, deve entende-la como um sistema institucionalizado de produção, consumo, distribuição e censura do saber jurídico influenciado pelas relações com a sociedade global, sendo que estas relações devem ser exteriorizadas (WARAT, 1995, p. 178). 


\section{A purificação antijusnaturalista}

Este nível de purificação é derivado da purificação político ideológica e WARAT (1995, p. 179) o enuncia da seguinte forma: "é falso supor que os juristas possam produzir, ao nível do pensamento científico, um raciocínio determinante do que deva ser visto como Direito justo e, consequentemente, postular um critério de validade para o Direito Positivo".

KELSEN critica a postura jusnaturalista de adoção da idéia de justiça como fundamento da validade para o Direito Positivo. Afirma que o Direito Natural tem uma proposta ideológica de fundamentação metafísica e política do critério de validade e, assumindo os fundamentos epistemológicos do positivismo científico, diferencia a concepção de validade e de valor.?

As normas de justiça são caracterizadas como relativas e subjetivas e, portanto, incompatíveis com a perspectiva positivista da Teoria Pura do Direito que busca um fundamento de validade objetivo. ${ }^{8}$ Assim, KELSEN, após o referido rompimento epistemológico com o Direito Natural, parte para a construção de um critério de validade que servirá de demarcação do campo teórico da Ciência do Direito, bem como para a formulação de seus enunciados e finalmente permitiria o reconhecimento teórico do fundamento de validade das normas jurídico-positivas (WARAT, 1995, p. 183). Cria-se a norma fundamental gnoseológica, suporte do pensamento normativista, que estabelece com exclusividade as condições das proposições da $\mathrm{Ci}$ ência Jurídica.?

Tem-se, portanto, que, à luz de uma teoria positivista, um determinado ordenamento jurídico terá como último fundamento de validade objetiva a sua conformidade com a norma hipotética e fundamental da ordem jurídica. Assim, uma determinada norma jurídica tem como fundamento de validade outra norma jurídica superior que por sua vez terá sua validade determinada pela norma imediatamente superior até chegar a Constituição que terá sua fundamentação dada pela pressuposta norma fundamental (CORRÊA, 1991, p. 12). Assim, uma determinada ordem jurídica é fundamentada através de um processo de desencadeamento lógico e a validez do Direito ganha um sentido hipotético ligado à norma fundamental. KELSEN afasta a possibilidade de um critério de validade metafísico, subjetivo ou valorativo para o ordenamento jurídico, pois, através de seu artifício metodológico, a validade de todo o ordenamento jurídico funda-se em si próprio.

Como já foi dito, o desencadeamento deste processo tem por objetivo impedir a nefasta influência da doutrina do Direito

7 O problema da justificação da ordem jurídica é transferido para a ética ou para a filosofia, percebe-se que este problema não é eliminado, mas simplesmente deslocado.

8 É justamente a busca por um critério objetivo de validade que diferencia o positivismo jurídico do Direito Natural.

9 A norma fundamental é um artifício metodológico utilizado por KELSEN para superar os apelos de fundamentação metafísica e valorativa. 
Natural que, através de um conjunto de classificações, fórmulas tópicas e conceitos, permeiam a Ciência Jurídica com ideologias. KELSEN critica o senso comum teórico de viés jusnaturalista e sua tentativa de legitimação da ordem dominante e estabelece uma fórmula neutra de validade para o ordenamento jurídico.

É neste ponto que WARAT (1995, p. 190) concentra sua crítica, pois afirma citando FERRAZ: "o papel ideológico de uma linguagem é produzido a partir de uma neutralização ou encobrimento de sua função. Isto pode ser realizado de duas maneiras: $1^{\circ}$ ) escondendo a presença inevitável do emissor de uma valoração e dando a impressão de que se trata de uma proposição sem sujeito - caso do Jusnaturalismo que propõe um sujeito transcendente ou uma referência direita à natureza; $2^{\circ}$ ) substituindo valorativas por fórmulas neutras caso da norma fundamental em KELSEN".

\section{A purificação antinaturalista ou anticausalista}

O enunciado deste nível de purificação é o seguinte: "é preciso evitar um sincretismo metodológico que obscureça a construção de um campo temático específico da Ciência do Direito e dilua os limites que lhe são impostos pela própria natureza do objeto" (WARAT, 1995, p. 190). Aqui a intenção é estabelecer a posição do Direito perante as demais ciências, para determinar a especificidade do conhecimento jurídico.
KELSEN separa as ciências da natureza das ciências sociais, que por sua vez são subdivididas em ciências sociais causais regidas pelo princípio da causalidade e em ciências sociais normativas regidas pelo princípio da imputação. Enquanto as primeiras são jogadas para o mundo do ser, as outras são jogadas para o mundo do dever-ser.

Nas ciências naturais existe uma conexão com o mundo do ser, com a realidade fática, e seu objeto (natureza) constitui um sistema ligado na forma de causa e efeito seguindo o princípio da causalidade. Assim, os elementos do real são ligados de tal forma que o primeiro seja pensado como causa do segundo.

Já nas ciências sociais, o seu objeto, a sociedade, ${ }^{10}$ é um complexo de elementos interligados pelo princípio da imputação. Portanto, para KELSEN, a sociedade é um conjunto de enunciados normativos e as verdadeiras ciências sociais, ou ciências sociais em sentido estrito, ${ }^{11}$ são aquelas que tem por objeto as normas determinantes da conduta humana, ou a conduta humana enquanto regulada por normas.

A partir dessas concepções a teoria Pura do Direito situa a Ciência Jurídica como uma ciência social normativa, um saber dirigido a conduta humana não como ela se realiza efetivamente, mas como deve ser: "de proposições explicativas do significado jurídico atribuído à conduta por um sistema de normas, as jurídicas." (WARAT, 1995, p. 194)

10 A sociedade, para KELSEN, é considerada como um complexo de ordens normativas (WARAT, 1995, p. 193).

11 Aqui a Psicologia, a História e a Sociologia são consideradas ciências sociais causais que se diferenciam apenas em grau, mas não em princípio, das ciências da natureza, pois adotam o princípio da causalidade. 
KELSEN insere neste ponto a distinção entre Direito e Ciência do Direito, entre normas jurídicas e as proposições da Ciência Jurídica, como afirma CORRÊA (1991, p. 10): "Chegamos, assim, à decisiva distinção metodológica na teoria kelsiana: a separação entre Direito e Ciência do Direito, tão enfatizada pelo autor. Trata-se da distinção entre Sollen ou normas de dever-ser (mandamentos, prescrições) e Sollsatze ou proposições normativas (enunciados ou juízos hipotéticos sobre as normas). A proposição jurídica como função de conhecimento ensina, declara ou descreve se uma norma existe ou é válida, quer dizer, se a norma é efetivamente estabelecida pela autoridade do direito como sentido (objetivo) de seu ato de vontade (subjetivo). Deste aspecto é ela verdadeira ou falsa. Já a norma prescreve um dever-ser produzido pela autoridade jurídica sendo que a prescrição não é verdadeira ou falsa mas válida ou inválida".

É a dissociação necessária entre saber e poder, onde o conhecimento é neutro e isento de influências volitiva-positivaideológica. Percebe-se a preocupação com a neutralidade da Ciência do Direito mas não com a neutralidade do Direito.

\section{A purificação intranormativa}

Faz-se necessário, agora, um processo de distinção da ciência Jurídica para com as outras ciências sociais normativas. Sendo este o enunciado apresentado: "para que haja uma ciência jurídica, em sentido estrito, é preciso que se proponham as noções de sanção e de órgão como princípios cate- gorias aptos para determinar, em relação às outras ciências sociais normativas, as diferenças específicas do objeto temático da Ciência do Direito" (WARAT, 1995, p. 206). Como se pode observar através do enunciado, neste nível e purificação, são os conceitos de sanção e órgão os elementos determinantes da especificidade da Ciência Jurídica.

Desta forma é possível determinar o Direito como uma técnica de motivação que provoca a conduta determinada por suas normas, através do vínculo de um juízo imputativo à conduta contrária à desejada com a ameaça de um ato de coerção aplicável de um órgão dotado de autoridade, por outra norma do próprio Direito Positivo. Obtém-se o conceito de sanção que seria o ato de coerção determinado como devido, mediante um enunciado imputativo da ordem jurídica (WARAT, 1995, p. 209).

Com este conceito de sanção é possível separar a ordem moral da ordem jurídica, pois a primeira não apresenta, em seu conteúdo, um ato de coerção. É uma técnica de motivação cuja a própria ordem não define sua sanções. A reação da ordem moral à conduta indesejável é colocada de forma automática e espontânea pela comunidade, carecendo de órgão. Na religião, a sanção é aplicada por um órgão de natureza divina; mesmo que aplicada neste mundo a sanção possui uma natureza transcendente. No Direito, a sanção é aplicada por uma autoridade cujo o poder deriva da própria organização comunitária. A sanção é socialmente imanente, sendo aplicada por um indivíduo que atua como órgão da ordem social. 
Percebe-se que a construção deste conceito de sanção estabelecido pela teoria Pura tem o mesmo objetivo dos níveis de purificação anteriores, ou seja, produzir conceitos ideologicamente neutralizados e desvinculados do modelo jusnaturalista; este modelo teria uma concepção de sanção como uma resposta eticamente justa e natural que legitimaria o poder dos órgãos estatais, o uso da força do Estado.

No entanto, o normativismo não supera a ideologização, consegue apenas modificar as significações ideológicas associadas ao conceito de sanção. Se antes o jusnaturalismo estabelecia um processo retórico, um processo de legitimação do uso da força do estado, a partir de uma concepção de sanção tem-se o mesmo processo de legitimação do uso da força estatal, mas, no entanto, utiliza-se novos argumentos como a neutralidade do Estado e a sua função de garantir a paz social. ${ }^{12}$ Assim, KELSEN atribui uma finalidade, mesmo que indireta, ao conceito de sanção, qual seja, a de garantir a paz social, a segurança coletiva. $\bigcirc$ uso da força estatal, a aplicação da sanção tem por objetivo garantir a paz social.

Percebe-se, portanto, a inserção de um objetivo para o Direito que estabelece um processo de legitimação ideológica que KELSEN nega e transforma, através da norma fundamental, em legalidade. Essa legalidade irá impor à teoria jurídica, segundo WARAT (1995, p. 218): "um sistema de legitimidade aparentemente neutro e utilitário que, em realidade, fundamente a obrigação de obediência à ordem jurídica (e política)".

\section{A purificação monista ou antidualista}

A purificação monista apresenta o seguinte enunciado: "é preciso tornar independente o conhecimento do Direito em relação aos pressupostos metodológicos dualistas, mediante os quais se constitui o sistema classificatório e os exemplos pragmáticos do modelo de ciência Jurídica como normal em nossos dias". (WARAT, 1995, p. 224)

O dualismo jurídico estabelecia concepções metodológicas predominantes na Ciência Jurídica, era uma condição metodológica fundamental que regia a definição dos problemas, a organização das estratégias de resolução, bem como a própria concepção de ciência. Este modelo, para KELSEN, produzia um conjunto de significações comprometidas ideologicamente, pois submetia o Direito e o Estado ${ }^{13}$ a uma ordem normativa metajurídica inscrita no sistema da natureza como condição de legitimação ética.

A Teoria Pura do Direito propõe a adoção de um critério monista, considerando o Direito como uma estrutura puramente normativa onde todos os problemas devem ser colocados e resolvidos como questões normativas. Assim, a busca de uma

12 O Direito para a Teoria Pura aparece como uma organização monopolizadora da força que serve para garantir a paz social. No entanto a própria Teoria Pura afirma que a busca do fim do Direito, a função na sociedade, é a lacuna que permeia a Ciência Jurídica de teorias ideológicas.

13 A tese monista identifica o Estado com o Direito, rejeitando a concepção dualista que o vê como entidade metafísica necessária. 
fundamentação fora da realidade normativa não é admissível para KELSEN que acaba por estabelecer um processo de autolegitimação do Direito através da norma fundamental.

KELSEN separa o mundo do ser, mundo dos indivíduos ou universo social, do mundo do dever-ser, mundo onde se processa a autolegitimação do direito e do Estado, independente da sociedade. Significa dizer que a legitimação do direito não se processa através dos valores sociais e sim através de uma legalidade reconhecida teoricamente através da norma fundamental. ${ }^{14}$

A Ciência do Direito fecha-se à realidade social com o objetivo de romper com as significações ideológicas produzidas pela dogmática jurídica. Substitui o núcleo teórico de inspiração idealista e humanista por uma modelo cartesiano com o objetivo de afastar as influências ideológicas impeditivas da verdade. No entanto, as teorias ideológicas continuam influenciando o processo de significações da Ciência Jurídica, escondidas sob o mito da neutralidade e da objetividade. $O$ silêncio da Teoria Pura a respeito da influência das teorias ideológicas na determinação do Direito não quer dizer que Ciência Jurídica não será contaminada por essas teorias, e mais, este silêncio facilita a sua função ideológica, pois sua significações ganham um status de neutralidade e objetividade sem revelar seu emissor.

\section{0 ensino jurídico tradicional}

Como já dissemos na introdução, o presente trabalho tem por objetivo a consolidação de uma perspectiva crítica acerca da Ciência do Direito. Perspectiva que desmascare a cotidiana reprodução de um conhecimento limitado imposto pela dogmática jurídica através do senso comum teórico dos juristas.

O senso comum teórico é colocado como um realidade indiscutível de significações que acabam por estabelecer o caminho que deve ser trilhado pelo acadêmico de Direito, pois esse é introduzido em um processo de conhecimento dominado pela dogmática jurídica de viés positivista. ${ }^{15} \mathrm{O}$ acadêmico não passa de um mero reprodutor da dogmática, um reprodutor que sequer conhece os pressupostos teóricos do que reproduz. Portanto, esse processo é dado de forma limitada e não possibilita ao acadêmico uma verdadeira visão do fenômeno jurídico. Como afirmar CORRÊA (1999, p. 15) “(...) a introdução em um novo campo de pesquisa, melhor, em uma nova ótica de análise em determinado campo do conhecimento humano não representa uma introdução em si, mas várias introduções possíveis, cada uma com sua própria racionalidade, seus próprios interesses, muitas vezes setorizados. Cabe ao professor-pesquisador-pedagogo a responsabilidade de abrir as portas e orientar o sentido da caminhada acadêmica".

14 WARAT faz uma interessante observação da visão kelseniana do pacto social: "Isto é o que nos sugere a norma fundamental, quando formulada da seguinte maneira: 'se $A$ manda e é geralmente obedecido, deve ser que $A$ mande e seja geralmente obedecido'. Eis a versão kelseniana do pacto social”. (1995, p. 277)

15 Não se está reduzindo o positivismo jurídico ao normativismo kelseniano, mas, no entanto, coloca-se a Teoria Pura do Direito como pedra fundamental para elaboração de uma Ciência do Direito de viés positivista. 
Faz-se necessário quebrar a ilusão criada pelo tradicional ensino jurídico, desmascarar sua real função escondida sob as sombras dos mitos da neutralidade e da objetividade, trazer à luz o que a dogmática jurídica esconde em seu discurso, ou seja, as ideologias e as contradições de um sistema que não acompanha a realidade social.

\section{Considerações finais}

Na perspectiva de WARAT, o presente trabalho apontou a limitação da matriz teórica da dogmática jurídica de viés positivista e principalmente para recuperação ideológica da teoria kelseniana. Sua impossibilidade de afastar as ideologias e seu papel na criação de novos mitos reproduzidos no ensino jurídico.

Possibilita-se assim, ao acadêmico, uma visão, mesmo que geral, da matriz do conhecimento reproduzido nas faculdades de Direito onde predomina o ensino tradicional. $\bigcirc$ objetivo é quebrar o mito da segurança, da neutralidade e da objetividade e reafirmar as possibilidades de novas abordagens acerca do Direito, afirmar que as sombras à nossa frente não refletem a realidade. Estabelecer a crise sem medo, pois, como afirma BUARQUE (1994, p. 19): "A crise é o primeiro ingrediente do desafio."

Neste desafio na abertura de novos caminhos, de novas perspectivas faz-se necessário fornecer ao acadêmico um novo instrumental teórico e crítico, possibilitador da ruptura com o velho paradigma limitador da realidade. Esse novo conhecimento crítico deve baixar à caverna gradativamente e com uma linguagem possível de identifi- cação de forma a consolidar-se. Neste processo de consolidação os interlocutores devem multiplicar-se, bem como a linguagem, é preciso ousar.

\section{Referências bibliográficas}

BOBBIO, Norberto. O positivismo jurídico: lições de filosofia do direito, tradução de Márcia Pugliesi, Edson Bini, Carlos E. Rodrigues. São Paulo: Ícone, 1995.

BUARQUE, Cristovam. A aventura da universidade. São Paulo: UNESP, Rio de Janeiro: Paz e Terra, 1994.

CORRÊA, Darcísio. A construção da cidadania: reflexões histórico-politicas. Ijuí: UNIJUÍ, 1999, p. 240.

. "Direitos humanos e sistema jurídico kelseniano". In Direito em Debate, n. 1, Ijuí: UNIJUÍ, out./91, p. 07-26.

JUNQUEIRA, Eliane Botelho. Faculdade de direito ou fábrica de ilusões? Rio de Janeiro: IDES: Letra Capital, 1999.

KELSEN, Hans. Teoria Pura do Direito, tradução de João Baptista Machado. 3. ed. São Paulo: Martins Fontes, 1991.

LAMPERT, Ernâni. Universidade, docência e globalização. Porto Alegre: Sulina, 1999.

PLATÃO. A República. Lisboa: Fundação Colousse Gulbenkian, 1996.

RODRIGUES, Horácio Wanderlei. Ensino jurídico e direito alternativo. São Paulo: Editora Acadêmica, 1993.

. Ensino jurídico: para que $(m)$ ? Florianópolis: Fundação Boiteux, 2000.

STRECK, Lênio Luiz. Hermenêutica Jurídica em crise: uma exploração da construção do Direito. Porto Alegre: Livraria do Advogado, 1999.

WARAT, Luís Alberto. Introdução geral ao direito: a epistemologia jurídica da modernidade. Vol. II, Porto Alegre: Fabris, 1995.

- A pureza do poder: uma análise crítica da teoria jurídica. Florianópolis: UFSC, 1983. 